\title{
Personalized training model for organizing blended and lifelong distance learning courses and its effectiveness in Higher Education
}

\author{
Gulmira Bekmanova $^{1}$ - Yerkin Ongarbayev ${ }^{1} \cdot$ Baubek Somzhurek $^{1} \cdot$ \\ Nurlan Mukatayev ${ }^{1}$
}

Accepted: 25 May 2021 / Published online: 18 June 2021

(c) The Author(s), under exclusive licence to Springer Science+Business Media, LLC, part of Springer Nature 2021

\begin{abstract}
The main goal of this research is to improve the personification of learning in higher education. The proposed flexible model for organizing blended and distance learning in higher education involves the creation of an individual learning path through testing students before the start of training. Based on the learning outcomes, the student is credited to the learning path. The training path consists of mandatory and additional modules for training; additional modules can be skipped after successfully passing the test, without studying these modules. The paper examines the composition of intelligent learning systems: student model, learning model and interface model. A student model is described, which contains the level of their knowledge, skills and abilities, the ability to learn, the ability to complete tasks (whether they know how to use the information received or not), personal characteristics (type, orientation) and other factors. The student's model is described by a mathematical formula. Thus, being described using logical rules, which have formed the basis for the software implementation of mixed and distance learning rules for lifelong learning courses. There is an interface model presented in the paper, and the results of the course of the proposed flexible model for the organization of mixed and distance learning "Digital Skills of a Modern Teacher in the Context of Distance Learning", as well as the face-to-face course "Digital Learning for Everyone" before the start of the pandemic which is close in its content to the course under study. Based on the results of the analysis, we introduced criteria for the effectiveness of the training course, proposed the weighting coefficients for evaluating the training course, carried out the assessment and drew conclusions.
\end{abstract}

Keywords Blended learning $\cdot$ E-learning $\cdot$ Ontological model $\cdot$ Artificial intelligence $\cdot$ Digital literacy $\cdot$ Personalized training $\cdot$ Intelligent systems

Gulmira Bekmanova

bekmanova_gt@enu.kz; gulmira-r@yandex.kz

1 LN Gumilyov Eurasian National University, Nur-Sultan, Kazakhstan 


\section{Introduction}

The essential parts of the distance learning system are teaching and information technologies, which are applied through the use of systems alike. Intelligent training systems provide a very high level of training dialogue with the user. It is for this reason that these systems are learners themselves. At the heart of this system is the knowledge base of the subject area being studied. The knowledge base should contain both objective knowledge, represented by the content of the educational area, and subjective knowledge of experts, which accumulate teaching methods and the unique experience of a specific teacher-expert. Intelligent learning systems should be presented in the form of systems that have a unique learning sequence in accordance with the specified criteria for the individual characteristics of the student. Personalization of training is an important aspect of organizing training that meets modern expectations. For lifelong learning, the most important thing is the ability to learn from anywhere, at a convenient time and following an individual way. In the context of distance learning during the COVID-19 pandemic, many educators who had previously taught students face-to-face, felt a digital literacy gap. This was the reason for the creation of the course "Digital Skills of a Modern Teacher in the Context of Distance Learning" based on a flexible personalized learning model. The main objective of this study is to create and implement a personalized learning model for the organization of blended and distance learning throughout life in higher education. The described model meets at least three criteria. The first criterion is the personalization of training, taking into account the input level of knowledge and skills, the possibility of training along an individual trajectory, taking into account the individual learning rate, without reference to time and place. To determine the initial level of knowledge, there is an admission test carried out in order to determine the degree of proficiency in digital skills, and the admission test allows enrolling in groups with a different educational program. The training program is flexible and allows skipping any of the modules by successfully passing the test; in case of test failure, the student continues training on the previous module.

The second criterion is the standardized organization of content where certain requirements are imposed for the structure and the content. The structure of content elements are as follows: an online lecture (a video lecture), assignments, an online discussion, tests and an exam. The video lecture is logically divided into fragments; each fragment ends with a question; the student gives an answer to each question in the system in natural language. A test is considered as passed based on the results of completing work assignments.

The third criterion is the intelligence of the system. The system should be intellectual, that is, be able to assess the knowledge of students without the teacher's participation.

Intelligent learning systems have three components. The first of these is the learner model. This model is a block with information about the student, the learning strategy chosen by them and the mistakes they make. The second component is a model of the learning process. It specifies the form of presenting information 
to the student and the type of assessment of the quality of the student's activity. This block includes the process of training the student of the course, as well as the establishment of a list of tests, analysis and assessment of the answer in natural language. In addition, this includes the final control procedures for the topic under study. The model interface is the link between the expert block of the intelligent training system and its other blocks (Golenkov et al., 2001).

In this work we have built a personalized, intelligent learning model with standardized content for the organization of blended and distance learning throughout life, which includes a learner model, a learning process model and an implementation of a learning interface.

The contribution of our work lies in the possibility of a widespread use of the described model, its relative ease of implementation, compliance with user expectations through personalization, and intellectual assessment of students' knowledge. The model is implemented on the example of open online courses of the L.N. Gumilyov Eurasian National University, which means that this model can be applied to platforms with massive open online courses. All the described results improve the quality of education as a whole, and the conducted sociological surveys confirm the relevance of the model.

The article consists of introduction, related works, student model, learning process model, interface model, results, discussions, conclusions, future work, and references.

\section{Related works}

The development of e-learning has increased the relevance of research methods, technologies, and assessment systems in higher education. (Alshargabi \& Aljawarneh, 2015, Lara et al., 2020, Aljawarneh, 2020). Distance learning and blended learning methods with electronic support devices are very well-known approaches in academic education. In most cases, direct personal contact between students and the teacher, as well as between students in groups, are important elements in organizing lectures and classes. However, the COVID-19 pandemic has significantly affected the organization of the educational process. The use of massive open online courses is an important aspect of e-learning especially during a pandemic (Zhang et al., 2021). The systematic review on massive open online courses (MOOCs) in higher education examined the research on the assessment of learning outcomes based on 65 peer-reviewed articles published between 2017 and 2019 (Wei et al., 2021). Interactive solutions for MOOC-based courses of Italian (De Notaris et al., 2021) and Kazakh universities (Bekmanova et al., 2020) are studied in many works. In particular, it has contributed to the almost universal introduction and development of distance or blended learning. We can see an increase in the urgency of the issue of quality assurance of distance and blended learning. Therefore, there have appeared new improvements in distance learning methods. For example, the work (Ożadowicz, 2020) proposes a modified blended learning method. Moreover, the work by Mohammed et al. (2020) looks at a model that supports the success of 
distance learning, especially in engineering education. The next promising trend that allows developing distance learning, is artiicial intelligence (Ortega, 2021).

Thus, the work (Kirsal Ever \& Dimililer, 2018) describes a gaze detection system for university students, which predicts student motivation in online sessions through the determination of eye positions. The database of the proposed study is organized in the form of images of gaze directions of people of different ages to the right, left and center. Back propagation neural networks were applied to classify the images in the direction of view, providing instructors with detailed information to understand students' interest in the subject and topics. The Personalized training model for organizing blended and distance lifelong learning courses discussed in this article was first proposed (Bekmanova \& Ongarbayev, 2020) as an ontological model of blended and distance learning based on an individual learning path. At present, the model has been fully implemented and introduced. Moreover, in this work we have evaluated the effectiveness of its application.

Zaoudi and Belhadaoui (2020) describes the potential for using artificial intelligence to improve the performance of distance learning platforms, information systems and network infrastructure during the COVID 19 pandemic, as well as examples of using artificial intelligence applications. The article shows that using artificial intelligence to improve the performance of distance learning servers is potentially possible in many areas. It is also worth noting that the use of artificial neural networks and LSTM neural networks for this purpose proves to be very promising.

The introduction of artificial intelligence technology for the development of distance multimedia platforms for sports education is described in the article (Mo et al., 2020).

Along with artificial intelligence, virtual, augmented reality and gamification are actively developing, since maintaining students' interest in semester-long distance learning courses and their involvement is a serious problem in the higher education system. The work (Klosowski, 2020) describes the possibilities of using social virtual reality platforms, which have wider spatial capabilities compared to $2 \mathrm{D}$, synchronous and asynchronous systems based on the Internet. Gamification is a promising method that adds an additional emotional layer to learning in the direction of increasing motivation. The article presents the results of a study of the active involvement of students using gamification in postgraduate distance learning taught at a British university. There is a discussion of the experience of students and recommendations for practitioners based on the principles of developing a gamified course.

All described works are aimed at improving the quality of education by improving the methods of blended and distance learning or improving technology. Some models improve personalization and increase motivation through a broader offering of interactive learning. In general, almost all effective models are based, to one degree or another, on artificial intelligence methods.

\section{Model of the learner}

The model of the learner contains all the necessary information about a specific student: the level of his knowledge, skills and abilities, the ability to learn, the ability to complete tasks (whether he knows how to use the information received), personal 
characteristics (type, orientation) and other factors. The model of the learner is dynamic, and it changes during the progress of the course, during his work with the system. Knowledge about the learner can be obtained in various ways, for example, by testing or diagnosing the learner's actions during the dialogue. The model of the learner is shown in Fig. 1.

The proposed model of the learner includes the main parameters of the model, according to the authors. Let us introduce the following notation:

(1) $\mathrm{L}_{\mathrm{m}}$ - model of the learner.

(2) $\mathrm{L}_{\mathrm{k}}$-level of knowledge.

(3) $\mathrm{L}_{\mathrm{r}}$-rate of learning.

(4) $\mathrm{L}_{\mathrm{t}}$-level of success in completing tasks.

(5) Ls-level of abilities and skills.

(6) $\mathrm{S}_{1}$-strategy of learning.

(7) $\mathrm{S}_{\mathrm{c}}$-structure of course.

Thus, the model of learner can be written as a set of learner's parameters:

$$
\mathrm{L}_{\mathrm{m}=} \mathrm{L}_{\mathrm{k}} \cdot \mathrm{L}_{\mathrm{r}} \cdot \mathrm{L}_{\mathrm{t}} \cdot \mathrm{L}_{\mathrm{s}} \cdot \mathrm{S}_{1} \cdot \mathrm{S}_{\mathrm{c}}
$$

The level of knowledge, the level of skills and abilities when enrolling in the course is determined by entrance testing of students. Entrance testing is performed by a closed multivariate test with one correct answer. The test contains $50 \%$ questions of difficulty level A, $30 \%$ of difficulty level B and $20 \%$ of questions of difficulty $\mathrm{C}$. Development of test items is done in accordance with the following requirements for difficulty levels (Table 1).

After determining the initial level of the student as beginner, elementary, intermediate, or advanced within the framework of the course in question, an enrollment

\section{Level of} knowledge

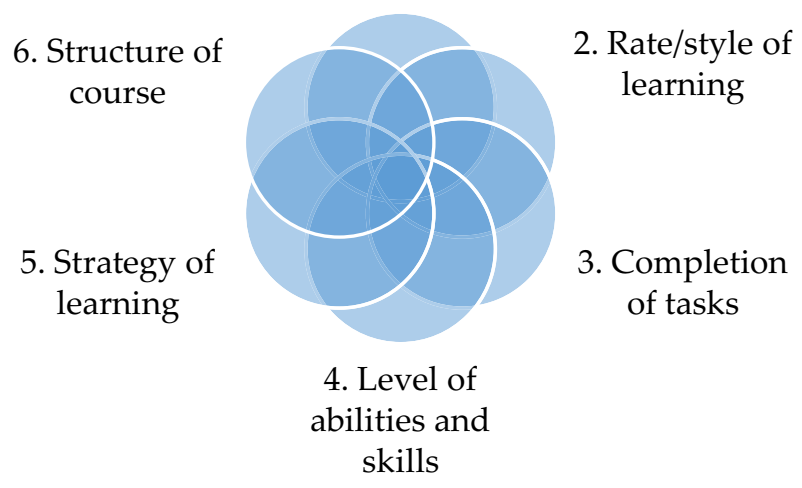

Fig. 1 The model of the learner 
Table 1 Digital skills levels

\begin{tabular}{llll}
\hline $\begin{array}{l}\text { Difficulty level of test } \\
\text { items }\end{array}$ & $\begin{array}{l}\text { Percentage of questions in one } \\
\text { test (\%) }\end{array}$ & Scoring range & Digital skills level \\
\hline A & 25 & $0-30$ & Beginner \\
A & 25 & $31-60$ & Elementary \\
B & 30 & $61-95$ & Intermediate \\
C & 20 & $96-120$ & Advanced \\
\hline
\end{tabular}

is carried out on the corresponding learning path. The maximum possible length of the presented course is 3 modules. Test takers with advanced level are included in the reserve for admission to courses requiring high professional skills (Bekmanova et al., 2020).

686 teachers were tested and, according to the results of the entrance testing, they were enrolled in groups with Kazakh and Russian languages of instruction, their distribution by levels of digital skills is shown in Fig. 2 .

Based on the results of entrance testing, 612 teachers were enrolled in the course, with the exception of 80 people who possess very high digital skills. They were enrolled in another course on the creation of electronic educational publications. The system tracks and accumulates the learner's success, which is available to both the instructor and the learner. The intelligent grading system uses fuzzy logic and it is described in detail (Barlybayev et al., 2020).

The percentage of certified and non-certified learners based on the course results in the context of 24 individual trajectories is shown in Fig. 3.

Based on the results of successful completion of the training, learners received certificates. The minimum percentage of learners who successfully completed the course in terms of learning trajectories was $72 \%$, the maximum was $100 \%$, the average percentage of certified learners in 24 trajectories was $82 \%$.

According to research conducted by the Technology and Social Change Group, or TASCHA, at the University of Washington's Information School, $49 \%$ of MOOC users have completed MOOC certification, and another 30\% have completed the

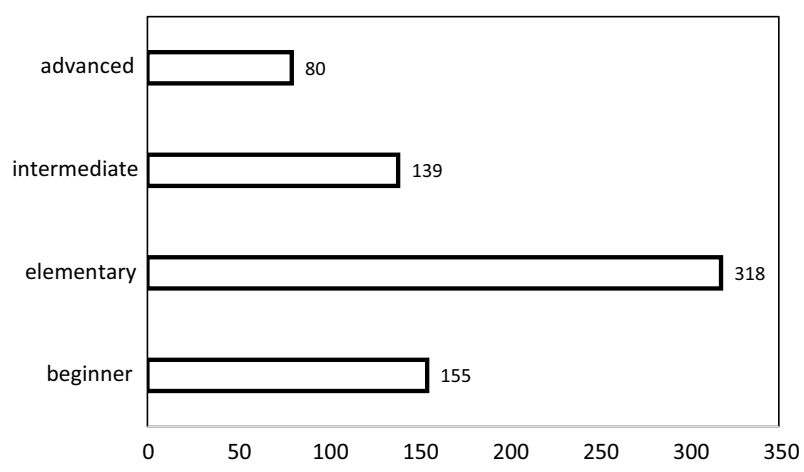

Fig. 2 Distribution by level of digital skills of university teachers 


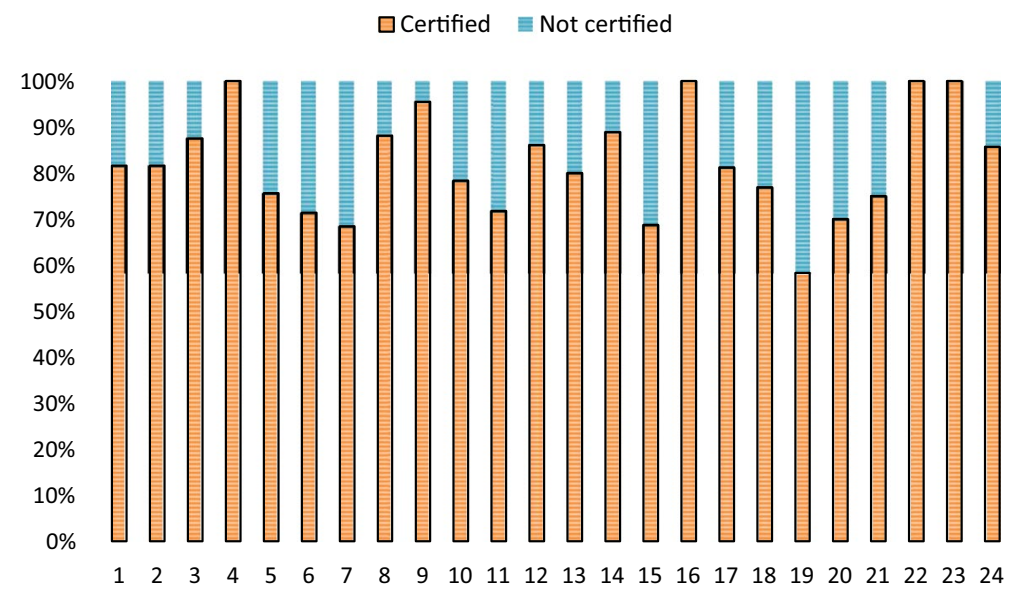

Fig. 3 Percentage of certified and non-certified trainees based on course results in the context of 24 individual trajectories

course. In our case, the average value of those who successfully completed the course with a certificate is $82 \%$, which is associated with the high motivation of teachers to improve digital skills.

\section{Model of the learning process}

Each of the modules includes mandatory modules, the passage of which ends with a test, and optional modules, which begin with passing the test and can be skipped if the test is successful. The ontological model consists of advanced training modules and tests and described in (Bekmanova et al., 2020).

The described ontological model should minimize the inevitable repetitions that arise during the study of the course and provide students and their teachers with the opportunity to form personalized educational trajectories.

Introduce the following meta notations in Table 2.

Table 2 Meta notation

\begin{tabular}{ll}
\hline Designation & Description \\
\hline Path & Set of trajectories \\
$\mathrm{M}_{\mathrm{m}}$ & Set of Mandatory modules \\
$\mathrm{M}_{\mathrm{o}}$ & Set of Optional modules \\
$\mathrm{T}_{\mathrm{m}}$ & Set of Mandatory module tasks \\
$\mathrm{T}_{\mathrm{o}}$ & Set of Optional module tasks \\
$\mathrm{Q}_{\mathrm{m}}$ & Set of Mandatory module tests \\
$\mathrm{Q}_{\mathrm{o}}$ & Set of Optional module tests \\
$\bullet$ & Concatenation \\
Sert, P & Predicates \\
\hline
\end{tabular}


To obtain a certificate, a prerequisite is the passage of two trajectories, on the presented ontological model they are named Path1, Path2, Path3. To obtain a certificate, you must successfully learn formula (2) for Path1 and Path2, or formula (3) for Path2 and Path3 in the form of production rules:

$$
\begin{aligned}
& \frac{\text { Path }_{1} \in \text { Path }_{\text {Path }} \in \text { Path }, \text { Path }_{1} \cdot \text { Path }_{2}}{\operatorname{sert}\left(\text { Path }_{1} \cdot \text { Path }_{2}\right)=1}
\end{aligned}
$$

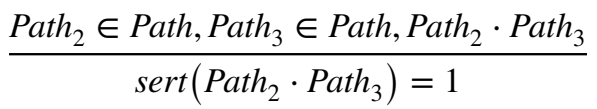

Within each trajectory, there is a subset of possible learning trajectories.

The Path 1 trajectory is considered to be successfully completed if the student has successfully completed the tasks of the required modules and successfully answered the tests of the required modules formula (4):

$$
\frac{\text { Path }_{1} \in \text { Path }, M_{m 1} \in M_{m}, M_{O 1} \in M_{O}, T_{m 1} \in T_{m}, T_{m 1}=1, T_{O 1} \in T_{O}, Q_{m 1} \in Q_{m}, Q_{m 1}=1, Q_{O 1} \in Q_{O}}{P(\text { Path })=1}
$$

The Path 1 trajectory is considered to be successfully passed if the student has successfully completed the tasks of the required modules (5):

$$
\frac{\text { Path }_{1} \in \text { Path }, M_{m 1} \in M_{m}, M_{O 1} \in M_{O}, T_{m 1} \in T_{m}, T_{m 1}=1, T_{O 1} \in T_{O}, Q_{m 1} \in Q_{m}, Q_{O 1} \in Q_{O}}{P\left(\text { Path }_{1}\right)=1}
$$

The Path 1 trajectory is considered to be successful if the student has successfully answered the tests of the required modules (6):

$$
\frac{\text { Path }_{1} \in \text { Path }, M_{m 1} \in M_{m}, M_{O 1} \in M_{O}, T_{m 1} \in T_{m}, T_{O 1} \in T_{O}, Q_{m 1} \in Q_{m}, Q_{O 1} \in Q_{O}, Q_{m 1}=1}{P\left(\text { Path }_{1}\right)=1}
$$

The Path 1 trajectory is considered to be successful if the student has successfully completed the tasks of the required modules and successfully answered the tests of the required modules and answered the tests of the optional modules by formula (7):

$$
\frac{\text { Path }_{1} \in \text { Path }, M_{m 1} \in M_{m}, M_{O 1} \in M_{O}, T_{m 1} \in T_{m}, T_{m 1}=1, T_{O 1} \in T_{O}, Q_{m 1} \in Q_{m}, Q_{m 1}=1, Q_{O 1} \in Q_{O}, Q_{o 1}=1}{P\left(\text { Path }_{1}\right)=1}
$$

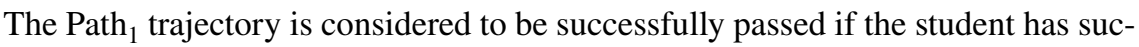
cessfully completed the tasks of the required modules and successfully answered the tests of the required modules and answered the tests of the optional modules formula (8):

$$
\frac{\text { Path }_{1} \in \text { Path }_{M_{m 1}} \in M_{m}, M_{O 1} \in M_{O,} T_{m 1} \in T_{m}, T_{m 1}=1, T_{O 1} \in T_{O}, Q_{m 1} \in Q_{m}, Q_{O 1} \in Q_{o} \cdot Q_{O 1}=1}{P\left(\text { Path }_{1}\right)=1}
$$




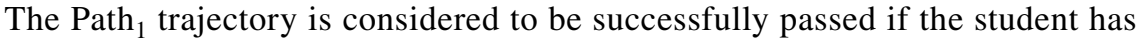
successfully completed the tasks of the required modules and answered the tests of the optional modules by formula (9):

$$
\frac{\text { Path }_{1} \in \text { Path }, M_{m 1} \in M_{m}, M_{O 1} \in M_{O}, T_{m 1} \in T_{m}, T_{m 1}=1, T_{O 1} \in T_{O}, Q_{m 1} \in Q_{m}, Q_{O 1} \in Q_{o}, Q_{O 1}=1}{P\left(\text { Path }_{1}\right)=1}
$$

The path Path 1 is considered to be successfully completed if the student has successfully completed the tasks of the required modules and completed the tasks of the optional modules formula (10):

$$
\frac{\text { Path }_{1} \in \text { Path }, M_{m 1} \in M_{m}, M_{O 1} \in M_{O}, T_{m 1} \in T_{m}, T_{m 1}=1, T_{O 1} \in T_{O}, T_{O 1}=1, Q_{m 1} \in Q_{m}, Q_{O 1} \in Q_{o}}{P\left(\text { Path }_{1}\right)=1}
$$

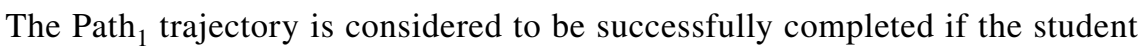
has successfully completed the tasks of the required modules and completed the tasks of the optional modules formula (11):

$$
\frac{\text { Path }_{1} \in \text { Path }, M_{m 1} \in M_{m}, M_{O 1} \in M_{O}, T_{m 1} \in T_{m}, T_{O 1} \in T_{O}, Q_{m 1} \in Q_{m}, Q_{m 1}=1, Q_{O 1} \in Q_{o}, Q_{O 1}=1}{P\left(\text { Path }_{1}\right)=1}
$$

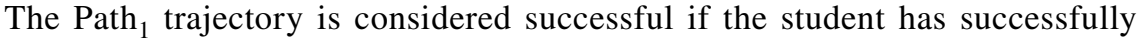
completed the tasks of the required modules and passed the tests of the optional modules formula (12):

$$
\frac{\text { Path }_{1} \in \text { Path }, M_{m 1} \in M_{m}, M_{O 1} \in M_{O} T_{m 1} \in T_{m}, T_{O 1} \in T_{O,} T_{O 1}=1, Q_{m 1} \in Q_{m}, Q_{m 1}=1, Q_{O 1} \in Q_{o}}{P\left(\text { Path }_{1}\right)=1}
$$

The production rules for trajectories 2 and 3 are written in a similar way.

The use of such logical rules makes it possible to describe the learning process model in a formal form, which, firstly, allows the implementation of the model in software, and secondly, it gives the prospect to apply Fuzzy Logic when the system makes a decision, which will further increase the flexibility of the model.

The structure of the course is shown in Fig. 4.

Both mandatory and optional modules can be implemented in both a blended learning model and a distance learning model. In the mixed model, it is assumed that it is practical exercises that are conducted face to face, and lectures can be conducted either online, offline, or face to face, in the flipped class model. In the distance learning model, all classes are held in a remote format. Each component of the model has an interface for interacting with students.

\section{Model interface}

The implemented model interface allows learning in traditional, blended or distance format. The course is implemented on mooc.enu.kz platform, where courses 
1.Online

lectures

6. Feedback

5. Final test

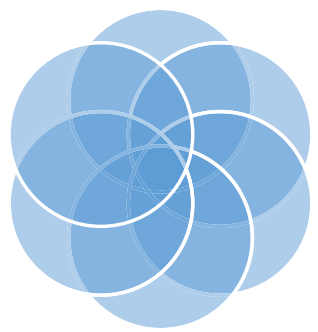

2. Tasks

3. Online

discussion

\section{Tests}

Fig. 4 The structure of course

are located open online courses of the L.N. Gumilyov Eurasian National University. The platform is based on moodle and it includes online lectures, assignments, quizzes, final tests, discussions and feedback (Fig. 5).

Distance learning can be done in synchronous and asynchronous modes, since digital content is fully prepared for all types of classes and control events. In the case of the subsequent implementation of an automatic feedback mechanism, learning can be done without a teacher. Figure 6 shows a fragment of the course.

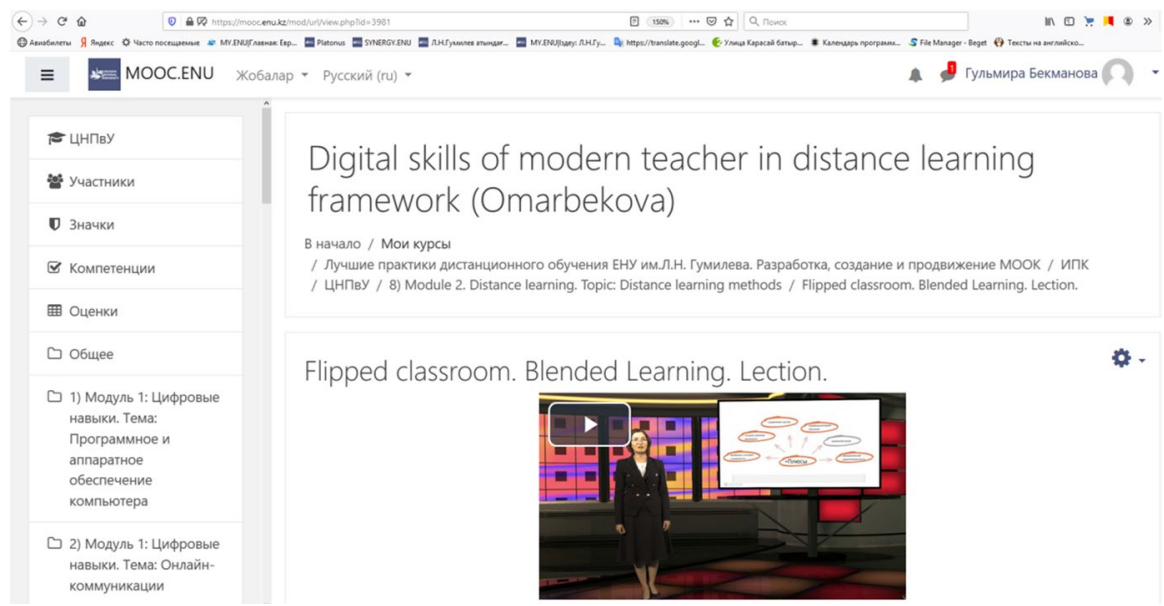

Fig. 5 Fragment of the course 


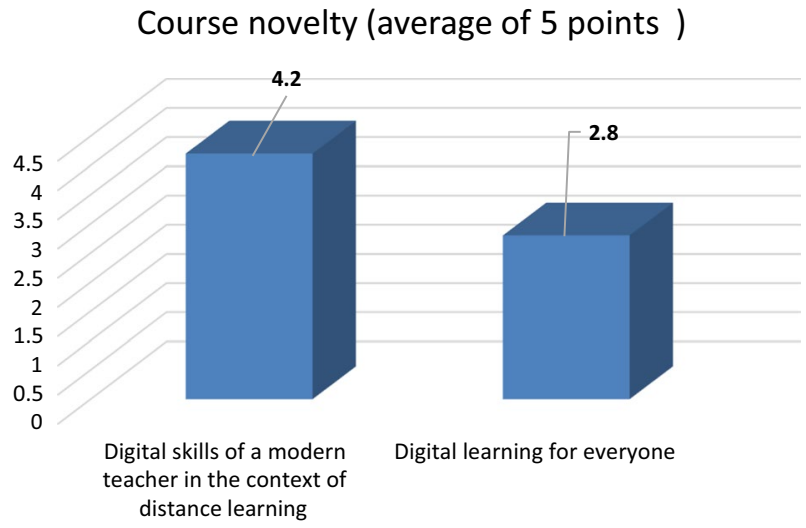

Fig. 6 Course novelty comparison

\section{Results}

The authors propose a personalized learner model of the LLL course "Digital Skills of a Modern Teacher in the Context of Distance Learning" built on the basis of a flexible personalized learning model based on admission tests to determine the initial level of knowledge and the degree of digital skills". An ontological model is used to generate a learning path; possible learning paths are described in general by production rules. The model interface is implemented using online courses and it is a link between the expert block of the intelligent learning system and its other blocks.

Table 3 shows comparative data for the two courses. Course 1 "Digital Skills of a Modern Teacher in the Context of Distance Learning" (course of study), as well as Course 2 "Digital Learning for Everyone", which took place in the traditional way before the start of the pandemic.

As presented in the data in Table 3, the course "Digital Skills of a Modern Teacher in the Context of Distance Learning" has a large number of students, which can be explained by teachers' need for digital skills in the context of the transition to distance learning during the pandemic. At the same time, the successful completion of the traditional course "Digital Learning for Everyone" is confirmed by the fact that $100 \%$ of the enrolled were successfully certified, while for course 1 the indicator was $82 \%$. This can be explained by the fact that the course "Digital Skills of a Modern Teacher in the Context of Distance Learning" was conducted using an

Table 3 Meta notation of sets, operations and predicates

\begin{tabular}{lll}
\hline Name of the course & $\begin{array}{l}\text { Number of course partici- } \\
\text { pants }\end{array}$ & $\begin{array}{l}\text { Number of verified } \\
\text { course participants }\end{array}$ \\
\hline $\begin{array}{l}\text { Course 1 "Digital skills of a modern teacher in the } \\
\text { context of distance learning" }\end{array}$ & 612 & 502 \\
\begin{tabular}{l} 
Course 2 "Digital learning for everyone" \\
\hline
\end{tabular} & 42 & 42 \\
\hline
\end{tabular}


online MOOC-type course, and the contact hours with a teacher accounted for only $50 \%$ of classes through distance technologies. This $18 \%$ difference in the number of successful certifications between Course 1 and Course 2 held face to face is considered expected.

Figures 6 and 7 show comparisons of the results of the survey on the novelty of the course.

Comparison shows that Course 2 "Digital Skills of a Modern Teacher in the Context of Distance Learning" is perceived by students as much newer (by 1.5 times), although the comparison of syllabuses showed insignificant differences in the content. Consequently, the greatest influence is exerted precisely by the possibility of skipping known material and focusing attention on materials that are new to the listener.

Comparison by this criterion shows that Course 2 "Digital Skills of a Modern Teacher in the Context of Distance Learning" is perceived by students as significantly more meeting their expectations (by 1.75 times).

\section{Discussion}

It is assumed that the proposed model is more effective because it is personalized and should meet the interests of the course participants. To test this hypothesis, we introduce the following criteria: "successful completion of the course", "novelty of the course", "compliance with students' expectations", and Results discussed in the paragraph. The choice of criteria and the weighting of the criteria were assigned following an open discussion with representatives of the Institute for Advanced Studies and Further Education and the Center for Quality Assessment of the university. The first criterion "successful completion of the course" will be estimated by the proportion of certified course participants in relation to the total number of participants and by the degree of its importance, the weight of this criterion will be 0.3 . The second criterion "novelty of the course" is assessed by the students' perception of

\section{Meeting expectations (average of 5 points )}

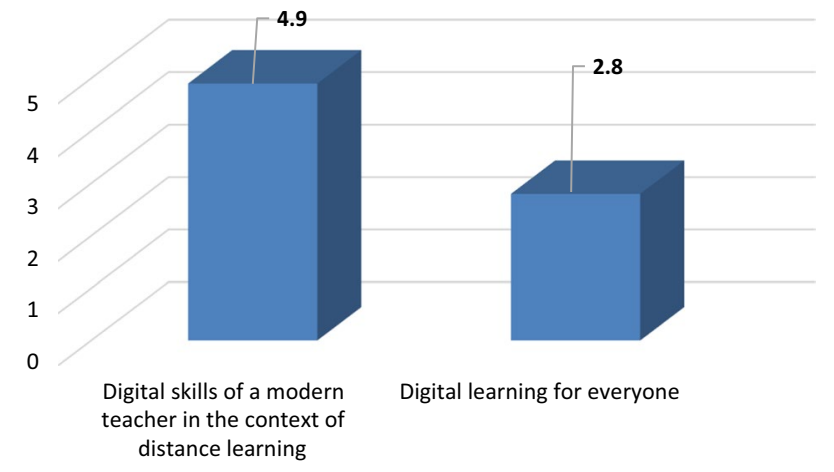

Fig. 7 Meeting expectation comparison 
the novelty of the course based on a survey. This criterion was introduced due to the fact that it is important for us to understand whether the personification of tining and the ability to skip elements of the module known to the student affect their perception of the novelty of the course. We will consider the criterion to be equivalent to the previous one, its weight will be 0.3 . The third criterion "compliance with students' expectations" is assessed according to the compliance with the expectations of students of the course based on a survey. Meeting students' expectations is most important and will be 0.4 .

Thus, the effectiveness of the course can be estimated by the formula (13):

$$
E=w_{c 1} * v_{c 1}+w_{c 2} * v_{c 2}+w_{c 3} * v_{c 3}
$$

где $w_{c i}$. is the weight $\mathrm{i}$ criterion.

$v_{c i}$ is the value of $\mathrm{i}$ criterion.

According to formula (13), we can estimate the course (Table 4).

The results of calculating the effectiveness of the course show that Course 1 "Digital Skills of a Modern Teacher in the Context of Distance Learning" is more effective and the result of the effectiveness of the course is 0.8 of the 1 maximum possible. Therefore, the proposed flexible model for the organization of mixed and distance learning is more effective than the previously used model of conducting similar courses. The results obtained confirm the chosen hypothesis. Similar comparisons were made with three other courses where similar results were obtained.

\section{Conclusion}

The article discusses elements of intelligent learning systems: student model, learning model and interface model. A formal description of the student's model allowed realizing a software implementation of the personalized training model for organizing blended and distance lifelong learning courses. At the same time, the student model has a perspective for development. The formal description of the learning model is presented using logical rules that formed the basis for the software implementation of blended and distance learning of the rules of lifelong learning courses. The proposed learning model allows improving the personalization of learning, which is confirmed by surveys of students on the basis of training. The implemented interface of the model is still quite simple, but it is possible to answer questions

Table 4 The results of calculating the effectiveness of the course in the context of criteria

\begin{tabular}{llllr}
\hline Name of the course/Criteria & $\begin{array}{l}\text { Successful } \\
\text { completion of the } \\
\text { course }\end{array}$ & $\begin{array}{l}\text { Novelty of } \\
\text { the course }\end{array}$ & $\begin{array}{l}\text { Compliance with } \\
\text { students' expecta- } \\
\text { tions }\end{array}$ & Total \\
\hline $\begin{array}{l}\text { Course 1 "Digital skills of a modern } \\
\text { teacher in the context of distance } \\
\text { learning" }\end{array}$ & 0.246 & 0.252 & 0.294 & 0.792 \\
$\begin{array}{l}\text { Course 2 "Digital learning for everyone" } \\
\text { Con }\end{array}$ & 0.3 & 0.168 & 0.168 & 0.636 \\
\hline
\end{tabular}


in natural language, which has never been done by other intelligent systems of this type. We have analyzed and compared by the proposed flexible model for the organization of mixed and distance learning the results of the courses "Digital Skills of a Modern Teacher in the Context of Distance learning" and the face-to-face course "Digital Learning for Everyone" before the start of the pandemic which is close in its content to the course under study. Based on the results of the analysis, we introduced criteria for the effectiveness of the training course, proposed weighting coefficients for evaluating the training course and carried out the assessment. Based on the results of evaluating the effectiveness of the course "Digital Skills of a Modern Teacher in the Context of Distance Learning", implemented on the basis of the proposed flexible model for the organization of mixed and distance learning, this course is found more effective due to the learning model.

The personalized training model for organizing blended and lifelong distance learning courses and its effectiveness in higher education uses the most promising models and methods of data science, such as ontological modeling, production rules; course effectiveness weights were introduced to allow further use of fuzzy logic in assessing effectiveness of the course. All of the above models and methods, together with the statistical evaluation carried out, can significantly improve the learning model in higher education. The main goal of the training system is quality teaching. The results obtained prove the improvement in the quality of teaching in this model. Therefore, the pedagogical value of the results obtained is high, since the improvement in the effectiveness of the course allows concluding about a more effective teaching model, the application of which must be expanded.

\section{Future work}

Further prospects of work, in our opinion, reside in the creation of more courses based on input testing and individualization of the learning trajectory with an improved system for assessing the level of mastering the material, which will be based on semantic search, optimal visualization of ontology and interactive dialogue. A new course for administrative and managerial personnel has already been developed, "Digital Personnel: Skills, Methods and Technologies for Effective Work", based on the same training model.

The models proposed in this article will be also developed further. In particular, the student model can be refined like the learning model. Each component can be described through logical rules, which will allow assessing the impact of each component and assessing the effectiveness of the student model. The learning model has the prospect of applying Fuzzy Logic when the system makes a student's decision to achieve the result of following the learning path, which will further increase the flexibility of the model. The interface of the model will be developed in case of demand for these courses and a larger number of students.

From the point of view of evaluating the effectiveness of the course, we will further develop the proposed model for evaluating the effectiveness of the course, and will study the influence of other criteria on the effectiveness of the course, depending on the content of the course; and in case new criteria are introduced, we will 
revise the weight coefficients. To revise the weighting factors, there will be created expert groups not only within the framework of one university, but with the involvement of colleagues from other universities, including foreign ones, to ensure the objectivity of the criteria for assessing the effectiveness of the course to improve the personification of learning in higher education.

\section{References}

Aljawarneh, S. A. (2020). Reviewing and exploring innovative ubiquitous learning tools in higher education. Journal of Computing in Higher Education, 32(1), 57-73.

Alshargabi, B., \& Aljawarneh, S. A. (2015). Innovations in educational technology and e-learning social networking. Recent Patents on Computer Science, 8(2), 100-105.

Barlybayev, A., Kaderkeyeva, Z., Bekmanova, G., Sharipbay, A., Omarbekova, A., \& Altynbek, S. (2020). Intelligent system for evaluating the level of formation of professional competencies of students. IEEE Access. https://doi.org/10.1109/ACCESS.2020.2979277

Bekmanova, G., \& Ongarbayev, Y. (2020). Flexible model for organizing blended and distance learning. Lecture notes in computer science (Vol. 12250). Cham: Springer. https://doi.org/10.1007/9783-030-58802-1_21

Bekmanova, G., Omarbekova, A., Kaderkeyeva, Z., \& Sharipbay, A. (2020). A model of intelligent massive open online course development. In Lecture notes in computer science (Vol. 12250). Springer. https://doi.org/10.1007/978-3-030-58802-1_20

De Notaris, D., Canazza, S., Mariconda, C., \& Paulon, C. (2021). How to play a MOOC: Practices and simulation. Entertainment Computing. https://doi.org/10.1016/j.entcom.2020.100395

Golenkov, V. V., Emelyanov, V. V., \& Tarasov, V. B. (2001). Virtual chairs and intellectual training systems. Artificial Intellect News, I(4), 3-13.

Kirsal Ever, Y., \& Dimililer, K. (2018). The effectiveness of a new classification system in higher education as a new e-learning tool. Quality and Quantity, 52, 573-582.

Klosowski, P. (2020). Artificial intelligence application to improve the performance of distance learning servers during the coronavirus pandemic threat period. In Signal processing-algorithms, architectures, arrangements, and applications conference proceedings, SPA (pp. 110-115).

Lara, J. A., Aljawarneh, S., \& Pamplona, S. (2020). Special issue on the current trends in e-learning assessment. Journal of Computing in Higher Education. https://doi.org/10.1007/ s12528-019-09235-w

Mo, L., Qin, Y., \& Li, Z. (2020). Design of distance multimedia physical education teaching platform based on artificial intelligence technology. Lecture Notes of the Institute for Computer Sciences, Social-Informatics and Telecommunications Engineering, LNICST (Vol. 340, pp. 303-314).

Mohammed, A. K., Zoghby, H. M., \& Elmesalawy, M. M. (2020). Remote controlled laboratory experiments for engineering education in the post-COVID-19 era: Concept and example. In 2nd novel intelligent and leading emerging sciences conference NILES (pp. 629-634).

Ortega, M. (2021). Computer-human interaction and collaboration: Challenges and prospects. Electronics, 10(5), 1-14. https://doi.org/10.3390/electronics10050616

Ożadowicz, A. (2020). Modified blended learning in engineering higher education during the COVID-19 lockdown-building automation courses case study. Education Sciences, 10(10), 1-20.

Wei, X., Saab, N., \& Admiraal, W. (2021). Assessment of cognitive, behavioral, and affective learning outcomes in massive open online courses: A systematic literature review. Computers and Education. https://doi.org/10.1016/j.compedu.2020.104097

Zaoudi, M., \& Belhadaoui, H. (2020). Adaptive E-learning: Adaptation of content according to the continuous evolution of the learner during his training. In ACM International Conference Proceeding Series 2020.

Zhang, J., Gao, M., \& Zhang, J. (2021). The learning behaviours of dropouts in MOOCs: A collective attention network perspective. Computers and Education. https://doi.org/10.1016/j.compedu.2021. 104189 
Publisher's Note Springer Nature remains neutral with regard to jurisdictional claims in published maps and institutional affiliations.

Gulmira Bekmanova received the B.S. degree in information systems from D. Serikbayev East Kazakhstan State Technical University, Ust-Kamenogorsk, Kazakhstan in 2004 and the M.Sc. degree in information systems from the same University in 2006, candidate of technical sciences on specialty: 13 May 2011 - Mathematical software for computers, complexes and computer network and the Ph.D. degree in Computer science, computer engineering and control from L.N. Gumilyov Eurasian National University, Kazakhstan in 2010. From 2004 to 2006, she was Assistant of Professor with the D. Serikbayev East Kazakhstan State Technical University, Kazakhstan. Since 2006 to 2019 she was a senior lecturer, an associate professor, a researcher of Artificial Intelligence Research Institute, the head of the Computer Science and Information Security Department, L.N. Gumilyov Eurasian National University, Kazakhstan. Since 2019 to 2020 she was the director of the Distance learning center, L.N. Gumilyov Eurasian National University, Kazakhstan. Since 2020 she is the head of the Digital Development and Distance learning department, L.N. Gumilyov Eurasian National University, Kazakhstan. She is the author of 3 monographs, 4 manuals and more than 100 articles, and 2 inventions.

Yerkin Ongarbayev received the B.S. degree in Jurisprudence from Karaganda Higher School of the Ministry of Internal Affairs, Karaganda, USSR in 1984, candidate of science in jurisprudence, Moscow USSR in 1990, and doctor of science in jurisprudence in 1999. From 1984 to 1996 he was a teacher, a senior teacher, an associate professor, the head of the department of the Karaganda higher school. From 2000 to 2003 he had position of an advisor to the Chairman of the Mazhilis of the Republic of Kazakhstan Parliament. From 2003 to 2007 he was the vice-rector, first vice-rector, vice-president with Kazakh Humanitarian Law University. From 2007-2010 he was the Chairman of the Science Committee of the Ministry of Education and Science of the Republic of Kazakhstan. From 2011 to 2020 he had positions of "Astana" university rector, vice rector of L.N. Gumilyov Eurasian National University, first vice-rector of the Academy of Law Enforcement Agencies and Chairman of the Committee on Religious Affairs of the Ministry of Religious Affairs and Civil Society, Kazakhstan. Since 2020 he is the vice rector of L.N. Gumilyov Eurasian National University, Kazakhstan. He is the author of 9 books, more than 130 articles, and 3 monographs.

Baubek Somzhurek received the B.S. degree in History in 1996 and candidate of science in History in 2001, from Al-Farabi Kazakh National University, Kazakhstan. From 1996 to 2004 he was a teacher, the head of the department, a vice-rector of the Arkalyk State Pedagogical Institute, Kazakhstan. From 2004 to 2006 he was a vice-rector of Abay Myrzaakhmet Kokshetau University, from 2006-2019 he had positions of associate professor, head of the center, dean of the Faculty, vice-rector of of L.N. Gumilyov Eurasian National University, Kazakhstan. From 2019 to 2020 he was a vice-president in International Astana University, Kazakhstan. Since 2020 he is the dean of the Social Sciences Faculty, L.N. Gumilyov Eurasian National University, Kazakhstan. He is the author more than 60 articles.

Nurlan Mukatayev received the B.S. degree in Automation and Informatization in Control Systems and M.Sc. degree in Heat Power Engineering from Shakarim University, Semey, Kazakhstan and the Ph.D. degree in Automation and Control from L.N. Gumilyov Eurasian National University, Kazakhstan in 2015. From 2015 to 2019 he was a specialist of National Testing Center, in Shakarim University, a deputy director of Technical Support Center, a senior lecturer of System Analysis and Control Department in L.N. Gumilyov Eurasian National University. From 2019 he was the head of the Department of Information Technologies. He has more than 50 publications. 